\title{
Biomarkers of systemic inflammation in farmers with musculoskeletal disorders; a plasma proteomic study
}

\author{
Bijar Ghafouri ${ }^{1,2 *}$, Anders Carlsson ${ }^{1}$, Sara Holmberg ${ }^{3}$, Anders Thelin ${ }^{4}$ and Christer Tagesson ${ }^{2}$
}

\begin{abstract}
Background: Farmers have an increased risk for musculoskeletal disorders (MSD) such as osteoarthritis of the hip, low back pain, and neck and upper limb complaints. The underlying mechanisms are not fully understood. Workrelated exposures and inflammatory responses might be involved. Our objective was to identify plasma proteins that differentiated farmers with MSD from rural referents.

Methods: Plasma samples from 13 farmers with MSD and rural referents were included in the investigation. Gel based proteomics was used for protein analysis and proteins that differed significantly between the groups were identified by mass spectrometry.

Results: In total, 15 proteins differed significantly between the groups. The levels of leucine-rich alpha-2-glycoprotein, haptoglobin, complement factor B, serotransferrin, one isoform of kininogen, one isoform of alpha-1-antitrypsin, and two isoforms of hemopexin were higher in farmers with MSD than in referents. On the other hand, the levels of alpha-2-HS-glycoprotein, alpha-1B-glycoprotein, vitamin D- binding protein, apolipoprotein A1, antithrombin, one isoform of kininogen, and one isoform of alpha-1-antitrypsin were lower in farmers than in referents. Many of the identified proteins are known to be involved in inflammation.

Conclusions: Farmers with MSD had altered plasma levels of protein biomarkers compared to the referents, indicating that farmers with MSD may be subject to a more systemic inflammation. It is possible that the identified differences of proteins may give clues to the biochemical changes occurring during the development and progression of MSD in farmers, and that one or several of these protein biomarkers might eventually be used to identify and prevent work-related MSD.
\end{abstract}

Keywords: Musculoskeletal disorder, Farmers, Proteomic, Systemic inflammation, Occupational medicine

\section{Background}

Farmers in industrialized countries have low morbidity in general and common disease entities as cancer and cardiovascular disorders are less frequent among farmers than in the general population [1]. By contrast, farmers have an increased risk of acquiring musculoskeletal

\footnotetext{
* Correspondence: bijar.ghafouri@liu.se

'Division of Community Medicine, Department of Medical and Health Sciences, Faculty of Health Sciences, Linköping University and Pain and Rehabilitation Center, Anaesthetics, Operations and Specialty Surgery Center, Region Östergötland, Linköping SE-581 85, Sweden

2Division of Neuro and Inflammation Science, Department of Clinical and Experimental Medicine, Linköping University, Occupational and Environmental Medicine Center, Heart and Medicine Center, Region Östergötland, Linköping, Sweden

Full list of author information is available at the end of the article
}

disorders (MSD), such as osteoarthritis of the hip, low back pain, and neck and upper limb complaints [1-3]. The reason for this is not known. We have previously demonstrated that the increased risk cannot be fully explained by known risk factors such as physical work load, psychosocial factors, or life style, indicating that other etiological factors must be involved. [2-4]. Interestingly, the prevalence of low back pain in farmers is associated not only with other musculoskeletal symptoms but also with chest discomfort, dyspepsia, symptoms from eyes, nose and throat mucous membranes, skin problems, work-related fever attacks, and primary care appointments due to digestive disorders [4]. This comorbidity points to the possibility that MSD in 
farmers may be part of a more systemic disorder with pathological changes in many organs and tissues. Since blood is in direct contact with all tissues, such changes are likely to be reflected in plasma [5] and quantitative changes in the plasma could thus serve as biomarkers of systemic effects. Moreover, plasma samples are readily available for investigation, thus making analysis of plasma a favorable alternative for examining laboratory signs of a systemic disorder. In a recent study serum samples from patient with discogenic chronic low back pain (DLBP) were analyzed by mass spectrometry to identify biomarkers for DLBP [6].

In this study, our objective was to identify plasma proteins that might differentiate farmers with MSD from matched rural referents. We focused on relatively abundant plasma proteins which can be quantified to the nanogram range using two-dimensional gel electrophoresis (2DE) with silver staining and subsequent identification by mass spectrometry (MS).

\section{Methods}

\section{Subjects}

The investigated subjects were selected from a prospective study cohort established with the intention to study health promoting factors related to farming and lifestyle [7]. All occupationally active male farmers born between 1930 and 1949 in nine rural municipalities in Sweden were identified in the Swedish National Farm Register and included in the cohort. The cohort represents a variety of farm types and geographical variation. The areas were chosen with consideration to known east-west and north-south cardiovascular disease gradients in the Swedish population [8] and to represent a variety of farm types and geographical variation over the country. Farmers were defined as men who owned or rented a farm and who spent at least $25 \mathrm{~h}$ per week farming. The occupational activity was checked with local representatives from the Federation of Swedish Farmers. To each farmer a rural referent, matched by age, sex and residential area, was sampled from the National Population Register. The rural referents were to be occupationally active in other than farming. Altogether 1220 farmers and 1130 rural non-farmers were eligible and included in the cohort. The farmers and the rural referents $(n=$ 2350) were invited to an extensive health survey including questionnaires, interviews, physical examinations and laboratory test [9].

The cross-sectional population-based survey identified farmers with MSD using a questionnaire with a number of items addressing symptoms from back, hip, knee, neck, forearms and shoulders. Information on symptoms from the musculoskeletal system was assessed by selfadministrated questionnaire [3]. The subjects were asked to indicate (yes or no) if they had ever (more than occasionally) had pain, aches or discomfort in the neckshoulder area, the low back, hips or knees. The questionnaire file shows this in more detail (see Additional file 1). Similar symptoms during the last year were also indicated. The subjects were asked to indicate whether they had sought medical advice or treatment for the various symptoms, and concerning low back and knee symptoms, whether they had been on sick leave due to the illness. A large number of farmers and non-farmers (89 \%) reported symptoms from musculoskeletal system. The farmers reported significantly more symptoms from low back and hips $[4,9]$.

This large material was used to identify farmers with symptoms from the musculoskeletal system only. Thirteen farmers working with swine confinement and cattle raising and their rural referents (Table 1) were selected and included in this explorative hypothesis generated study.

\section{Sample preparation}

All samples were blinded before analysis. Plasma from farmers and referents were prepared at the same time and not separately. $50 \mu \mathrm{l}$ of plasma was applied onto an albumin \& IgG Depletion column (GE Healthcare). Albumin and IgG were removed according to the manufacturer's recommendation. The samples were then desalted and lyophilized. The protein concentration was determined according to Bradford [10].

\section{2-DE analysis}

The lyophilized proteins were dissolved in $0.20 \mathrm{ml}$ urea sample solution according to Görg [11]. 2-DE was performed in a horizontal 2-DE setup (IPGphore and Multiphore from GE Healthcare), as described in detail previously [12] and essentially according to Görg [11]. The samples (containing $50 \mu \mathrm{g}$ protein for analytical gels and $900 \mu \mathrm{g}$ for preparative gels) were applied by in-gel rehydration (according to the manufacturer's instructions)

Table 1 Musculoskeletal symptoms among farmers and referents included in this study

\begin{tabular}{llll}
\hline Musculoskeletal symptoms & Farmers & Referents & p-value \\
& $N=13$ & $N=11$ & \\
\hline Neck and shoulder pain & 9 & 6 & $\mathrm{~ns}$ \\
Hands and forearms(numbness) & 4 & 4 & $\mathrm{~ns}$ \\
Hands and forearms(nocturnal pain) & 1 & 2 & $\mathrm{~ns}$ \\
Low back pain & 6 & 3 & $\mathrm{~ns}$ \\
Ischialgia & 5 & 1 & $\mathrm{~ns}$ \\
Hips problems & 10 & 5 & $\mathrm{~ns}$ \\
Groin-thigh pain & 4 & 3 & $\mathrm{~ns}$ \\
Knee joint problems & 8 & 2 & $\mathrm{~ns}$ \\
All symptoms & 13 & 5 & 0.007 \\
\hline
\end{tabular}


for $12 \mathrm{~h}$ using low voltage $(30 \mathrm{~V})$ in $\mathrm{pH} 4-7$ IPGs. The proteins were then focused for up to 32000 Vhs at a maximum voltage of $8000 \mathrm{~V}$. IPGs were either used immediately for second dimensional analysis, or stored at $-70{ }^{\circ} \mathrm{C}$ until analyzed. The second dimension (SDS-PAGE) was carried out by transferring the proteins to gradient gels cast on GelBond PAG film (0.5/180/245 mm, $11-18 \% \mathrm{~T}$, $1.5 \% \mathrm{C}, 33-0 \%$ glycerol) running at $30 \mathrm{~mA}$ and up to $1000 \mathrm{~V}$ for about $5 \mathrm{~h}$. In analytical gels, separated proteins were detected by silver staining according to Schevchenko as described previously [12]. The preparative gels, for MS analysis, were fluorescently stained with SYPRO Ruby [12]. All staining and washing steps were performed with continuous gentle agitation. The protein patterns were analyzed as digitized images, using a CCD camera in combination with a computerized imaging 12-bit system designed for evaluation of 2-DE patterns. The amount of protein in a spot was assessed as background corrected optical density, integrated over all pixels in the spot and expressed as integrated optical density (IOD). In order to correct for differences in total silver stain intensity between different 2-DE images, the amounts of the compared protein spots were quantified as optical density for individual spot per total protein intensity of all spots in the same gel. Thereby ppm-values (parts per million) for all proteins were generated that were evaluated for differences between the groups.

\section{Protein identification}

Protein spots were excised using a homemade spot picker. The picked protein spots were digested with trypsin (Promega/SDS Biosciences, Falkenberg, Sweden) as described previously [13]. The trypsinated peptides were applied to mass spectrometry for protein identification. The dried tryptic samples from fluorescently stained proteins were dissolved in $6 \mu \mathrm{l}$ of $0.1 \%$ formic acid. Peptides were analyzed using an on-line nano-flow HPLC system (EASY-nLC; Proxeon, Bruker Daltonics) in conjugation with the mass spectrometer HCTultra PTM Discovery System (Bruker Daltonics) as previously described [13]. LC-MS/MS spectra were processed by Bruker Daltonics DataAnalysis 3.4 (Bruker Daltonics, Bremen, Germany) and resulting MS/MS data were searched in NCBInr and Swiss-Prot database on MASCOT server: www.matrixscience.com Database search parameters were set as follows: the enzyme trypsin was used; up to one missed cleavage was allowed; fixed modification included were carbamidomethylation of cysteine and oxidation of methionine; mass tolerance for MS precursor ion was $0.8 \mathrm{Da}$ and for MS/MS fragment ion was $0.6 \mathrm{Da}$; and charge states were varied. Criteria for identification of a protein were at least 3 peptides of the protein should be identified with a MASCOT score over 25 and an expectation value $<1$. The mass list generated from the major peaks of the MALDI spectra was submitted to a database search (NCBI or SWISSPROT) using MS-FIT search engines. Restrictions were placed on species (Human), mass tolerance (50 ppm), maximum missed cleavages by trypsin (up to 1 ) and cysteine modification by carbamidomethylation.

\section{Statistical analysis}

Non-parametric Mann-Whitney $U$ test was used as statistical method to calculate significant differences between groups. A $p<0.05$ was considered statistically significant. All results are given as mean \pm standard deviation. IBM SPSS Statistics 20 was used as statistical software.

\section{Results}

\section{2-DE analysis and mass spectrometry}

To determine proper 2DE conditions for the analysis to be made, plasma proteins were separated in the $\mathrm{pI}$ ranges 3-10 and 4-7 (first dimension) followed by SDSPAGE (second dimension). As illustrated in Fig. 1, most of the spots detected in $\mathrm{pI}$ range 3-10 were also detected in the pI range 4-7 (about $90 \%$ ). The marked areas in Fig. 1 illustrate the good resolving power when using IPGs in pI range 4-7 compared to 3-10. A few proteins (Fig. 1a, dashed squares9 with $\mathrm{pI}$ outside the $4-$ 7 range were lost. Due to the good separation in the pI range 4-7 we decided to analyze all samples using IPGs 4-7. Mapping of the plasma proteome in the pI range 4-7 was performed by mass spectrometry. Seventy five spots could be identified (Table 2, Fig. 2). According to the accession number these identified protein spots represent 20 different proteins. Several of the identified proteins were expressed as different isoforms due to posttranslational modifications such as glycosylation and phosphorylation.

\section{Protein changes in farmers with MSD compared to rural referents}

More than 200 protein spots were detected in all samples. To investigate possible differences in the plasma proteomes of farmers with MSD and rural referents, protein spots present in at least $50 \%$ of the gels in either group were matched, quantified for intensity, and compared between the groups. Proteins whose concentrations were statistically different in the two groups were then identified using mass spectrometry. As shown in Table 3, the levels of leucine-rich alpha-2-glycoprotein, haptoglobin, complement factor $\mathrm{B}$, serotransferrin, one isoform of kininogen (spot1507), one isoform of alpha-1antitrypsin (spot 2404), and two isoforms of hemopexin (spots 6603 and 7602) were higher in farmers with MSD than in rural referents. On the other hand, the levels of alpha-2-HS-glycoprotein, alpha-1B-glycoprotein, vitamin 

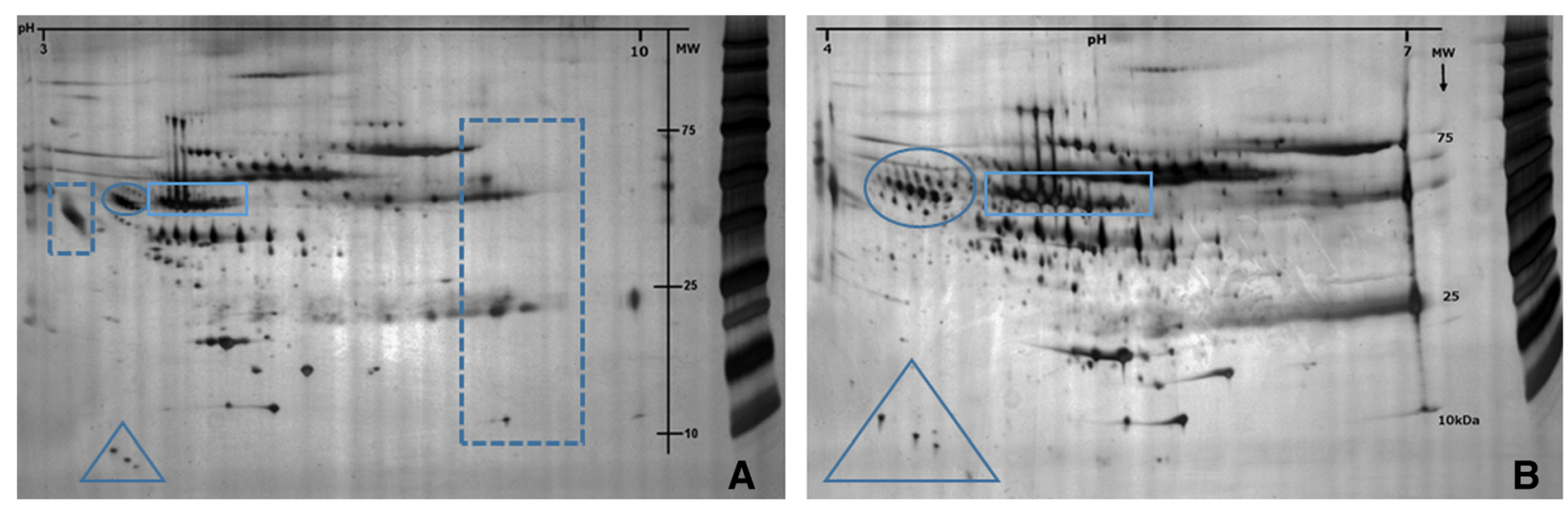

Fig. 1 Comparison between plasma protein separation in pl range of 3-10 (a) and 4-7 (b). The marked areas are some example of the improved resolution using IPGs 4-7

D- binding protein, apolipoprotein A1, antithrombin, one isoform of kininogen (spot 2607), and one isoform of alpha-1-antitrypsin (spot 3802) were lower (Table 2). Figure 3 pinpoints the statistically differing proteins on a 2DE gel, while Fig. 4 illustrates how the different isoforms of kininogen, alpha-1-antitrypsin, and hemopexin were quantitatively expressed in farmers with MSD and referents, respectively.

\section{Discussion}

Using 2-DE and mass spectrometry proteomic techniques, we were able to identify 15 proteins that were present differently in the plasma of farmers with MSD and their matched rural referents. Several of the proteins with plasma levels higher among farmers than among referents are well known as mediators or indicators of inflammation. For example, complement factor $B$ is essential for complement activation via the alternate pathway and so plays an important role in inflammatory conditions such as arthritis [14-16] and muscle inflammation [17]. Haptoglobin is established as an inflammation-inducible plasma protein [18] that exerts a regulatory activity on immune cell responses and host immunity [19]. Accordingly, haptoglobin was found to be a monocyte chemoattractant whose chemotactic potential was mediated, at least in part, by its interaction with chemokine (C-C motif) receptor 2 [20]. Recently, Park and co-workers demonstrated that the $\mathrm{C}$-terminal haptoglobin fragment is generated by plasmin in local inflammatory environments, suggesting that this fragment might be applied as a novel biomarker for the diagnosis and prognosis of inflammatory joint diseases such as rheumatoid arthritis [21]. Hemopexin belongs to the acute phase reactants, the synthesis of which is induced after inflammation. Aside from a systemic role in preventing heme-mediated oxidative stress, hemopexin might act as a local antioxidant at sites of injury and so play a role in inflammation [22].

Analogously, some of the proteins with plasma levels lower among the farmers than among the referents (Table 3) are known to have anti-inflammatory properties and actions. Thus, antitrombin III has been shown to inhibit cytokine and tissue factor production in endothelial cells [23], attenuate CD11b/CD18 expression in activated neutrophils and monocytes [24], suppress granule secretion in activated platelets [25], prevent apoptosis of hepatocytes [26, 27], and improve endotoxin-induced acute lung injury in rats [28]. Alpha2-HS-glycoprotein a multifunctional molecule that may serve as an inhibitor of systemic inflammation in mice [29] and humans [30, 31]; notably, its serum levels were significantly decreased in patients with RA [32, 33]. Vitamin D-binding protein (VDBP) is primarily known as a transport protein but was found to be downregulated in serum of experimental animals with systemic inflammation [34] and patients with sepsis [35, 36]. Moreover, $\mathrm{Oh}$ and coworkers recently found this protein to be down-regulated in serum of patients with carpal tunnel syndrome [37], a condition causing pain, impairment, and disability. The molecular mechanisms connecting inflammation with decreased VDBP are not clear, but because VDBP is a precursor for macrophage activating factor (MAF) it may be speculated that the decreased levels reflect increased formation of MAF and ensuing activation of macrophages [38] and neutrophils [39] at sites of inflammation. Alternatively, MAF may function positively by causing death of the macrophages when activated macrophages are no longer needed at the site of inflammation [40] Clearly, much further investigation is needed to elucidate why farmers with MSD appear to have decreased serum levels of VDBP.

One of the most important aspects of using 2DE is the capability of resolving many post-translationally modified 
Table 2 Identified proteins in plasma by nLC-MS/MS

\begin{tabular}{|c|c|c|c|c|c|c|}
\hline Spot $\mathrm{Nr}$ & Protein & SwissProt & $\mathrm{Mw} / \mathrm{pl}$ & Score & Sequence coverage [\%] & $\mathrm{Nr}$ of unique peptides \\
\hline 1 & Alpha-1-antitrypsin & P01009 & $46878 / 5.37$ & 194 & 21 & 7 \\
\hline 2 & Alpha-1-antitrypsin & & & 474 & 33 & 12 \\
\hline 3 & Alpha-1-antitrypsin & & & 382 & 32 & 15 \\
\hline 4 & Complement factor B & P00751 & 86847 / 6.67 & 225 & 12 & 10 \\
\hline 5 & Complement factor B & & & 266 & 16 & 12 \\
\hline 6 & Complement factor B & & & 339 & 15 & 15 \\
\hline 7 & Complement factor B & & & 252 & 15 & 14 \\
\hline 8 & Alpha-1B-Glycoprotein & P04217 & $54790 / 5.56$ & 51 & 1 & 6 \\
\hline 9 & Alpha-1B-Glycoprotein & & & 108 & 7 & 3 \\
\hline 10 & Alpha-1B-Glycoprotein & & & 142 & 12 & 5 \\
\hline 11 & Serotransferrin & P02787 & 79294 / 6.81 & 414 & 19 & 13 \\
\hline 12 & Serotransferrin & & & 988 & 52 & 31 \\
\hline 13 & Serotransferrin & & & 889 & 42 & 28 \\
\hline 14 & Serotransferrin & & & 1107 & 49 & 31 \\
\hline 15 & Serotransferrin & & & 1078 & 49 & 31 \\
\hline 16 & $\mathrm{~N}$-acetylmuramoyl-L-alanine amidase & Q96PD5 & $62748 / 7.25$ & 31 & 1 & 1 \\
\hline 17 & $\mathrm{~N}$-acetylmuramoyl-L-alanine amidase & & & 67 & 3 & 2 \\
\hline 18 & $\mathrm{~N}$-acetylmuramoyl-L-alanine amidase & & & 98 & 3 & 1 \\
\hline 19 & Hemopexin & P02790 & $52385 / 6.55$ & 212 & 14 & 6 \\
\hline 20 & Hemopexin & & & 306 & 23 & 11 \\
\hline 21 & Hemopexin & & & 314 & 26 & 12 \\
\hline 22 & Hemopexin & & & 329 & 25 & 11 \\
\hline 23 & Hemopexin & & & 298 & 15 & 10 \\
\hline 24 & Hemopexin & & & 277 & 20 & 9 \\
\hline 25 & Kininogen & P01042 & 72996 / 6.34 & 321 & 11 & 6 \\
\hline 26 & Kininogen & & & 308 & 9 & 5 \\
\hline 27 & Kininogen & & & 203 & 10 & 6 \\
\hline 28 & Hemopexin & P02790 & $52385 / 6.55$ & 266 & 20 & 8 \\
\hline 29 & Hemopexin & & & 49 & 2 & 1 \\
\hline 30 & Beta-2-Glycoprotein 1 & P02749 & 39584 / 8.34 & 172 & 16 & 5 \\
\hline 31 & Kininogen & P01042 & 72996 / 6.34 & 127 & 8 & 4 \\
\hline 32 & Kininogen & & & 275 & 17 & 8 \\
\hline 33 & Kininogen & & & 236 & 13 & 8 \\
\hline 34 & Kininogen & & & 254 & 15 & 8 \\
\hline 35 & Alpha-1-antitrypsin & P01009 & $46878 / 5.37$ & 962 & 45 & 17 \\
\hline 36 & Alpha-1-antitrypsin & & & 730 & 43 & 18 \\
\hline 37 & Alpha-1-antitrypsin & & & 1009 & 47 & 17 \\
\hline 38 & Alpha-1-antitrypsin & & & 509 & 42 & 16 \\
\hline 39 & Vitamin D-binding protein & P02774 & $54526 / 5.40$ & 476 & 36 & 16 \\
\hline 40 & Alpha-1-antitrypsin & P01009 & $46878 / 5.37$ & 620 & 51 & 19 \\
\hline 41 & Vitamin D-binding protein & P02774 & $54526 / 5.40$ & 381 & 25 & 11 \\
\hline 42 & Antithrombin III & P01008 & $53025 / 6.32$ & 333 & 25 & 10 \\
\hline 43 & Leucine-rich alpha-2-glycoprotein & P02750 & 38382 / 6.45 & 224 & 17 & 6 \\
\hline 44 & Leucine-rich alpha-2-glycoprotein & & & 131 & 14 & 5 \\
\hline
\end{tabular}


Table 2 Identified proteins in plasma by nLC-MS/MS (Continued)

\begin{tabular}{|c|c|c|c|c|c|c|}
\hline 45 & Leucine-rich alpha-2-glycoprotein & & & 134 & 17 & 4 \\
\hline 46 & Haptoglobin & P00738 & $45861 / 6.13$ & 302 & 21 & 9 \\
\hline 47 & Haptoglobin & & & 273 & 26 & 10 \\
\hline 48 & Haptoglobin & & & 296 & 27 & 10 \\
\hline 49 & Zinc-Alpha-2-glycoprotein & P25311 & $34465 / 5.71$ & 223 & 17 & 7 \\
\hline 50 & Zinc-Alpha-2-glycoprotein & & & 226 & 24 & 8 \\
\hline 51 & Clusterin & P10909 & $53031 / 5.89$ & 219 & 17 & 7 \\
\hline 52 & Clusterin & & & 203 & 14 & 7 \\
\hline 53 & Clusterin & & & 331 & 22 & 9 \\
\hline 54 & ApoA1 & P02647 & $30759 / 5.56$ & 419 & 44 & 13 \\
\hline 55 & ApoA1 & & & 775 & 62 & 16 \\
\hline 56 & ApoA1 & & & 4287 & 53 & 14 \\
\hline 57 & ApoA1 & & & 850 & 48 & 8 \\
\hline 58 & Haptoglobin & P00738 & $45861 / 6.13$ & & & 2 \\
\hline 59 & Haptoglobin & & & & & 2 \\
\hline 60 & Transthyretin & P02766 & $15887 / 5.5$ & 4357 & 69.4 & 11 \\
\hline 61 & Transthyretin & & & 8483 & 64.6 & 7 \\
\hline 62 & ApoCIII & P02656 & $8800 / 4.7$ & & 65 & 4 \\
\hline 63 & ApoCIII & & & & 65 & 4 \\
\hline 64 & ApoAll & P02652 & $9300 / 6.5$ & & 56 & 5 \\
\hline 65 & ApoCll & P02655 & $8900 / 4.7$ & & 96 & 6 \\
\hline 66 & Alpha-2-HS-Glycoprotein & P02765 & $39325 / 5,4$ & 60245 & 22.9 & 9 \\
\hline 67 & Alpha-2-HS-Glycoprotein & & & 60245 & 20.4 & 8 \\
\hline 68 & Alpha-2-HS-Glycoprotein & & & 60245 & 20.4 & 8 \\
\hline 69 & Alpha-2-HS-Glycoprotein & & & 60245 & 20.4 & 8 \\
\hline 70 & Haptoglobin & P00738 & $45861 / 6.13$ & 14986 & 24.1 & 11 \\
\hline 71 & Haptoglobin & & & 12798 & 23.2 & 8 \\
\hline 72 & Haptoglobin & & & 12728 & 21.9 & 8 \\
\hline 73 & Haptoglobin & & & 60393 & 28.3 & 11 \\
\hline 74 & Haptoglobin & & & 12798 & 23.2 & 8 \\
\hline 75 & Haptoglobin & & & 12728 & 21.9 & 8 \\
\hline
\end{tabular}

The spot numbers refer to marked protein spots in Fig. 1

proteins that may appear as isoforms. We identified two isoforms of hemopexin that both were present in higher amounts in the plasma of farmers (Table 3, Fig. 4). Moreover, we identified two proteins (kininogen and alpha-1antitrypsin) that were present differently in the plasma of farmers and referents depending on isoform, i.e., one isoform was present in a higher amount in the farmer group $v s$ the referent group, and another isoform was present in a higher amount in the referent group $v s$ the farmer group (Table 3, Fig. 4). While we are unable to conclusively explain these findings, it can be noted that these proteins, too, are being associated with inflammatory processes and diseases. Thus, kininogen is the precursor of bradykinin, a well-known mediator of inflammation and pain [41-43] that plays a crucial role in rheumatoid arthritis [44]. Alpha- 1-antitrypsin can exert anti-inflammatory activity in many tissues and organs including the musculoskeletal system; notably, low levels of alpha-1-antitrypsin have been suggested to contribute to the development of rheumatoid arthritis [45] and MSD [46]. Yet, changes in isoforms of kininogen, alpha-1-antitrypsin, and hemopexin have not previously been reported. We do not know the exact chemical nature of the isoforms found in our study and are currently attempting to ascertain post-translational modifications. Characterization of the chemical nature of these protein isoforms, determination of the tissue(s) that produce them, and the relationship between these isoforms and other interacting proteins-all of these, as they relate to the causal events of MSD, may lead to a further understanding of the progression to MSD in farmers. 


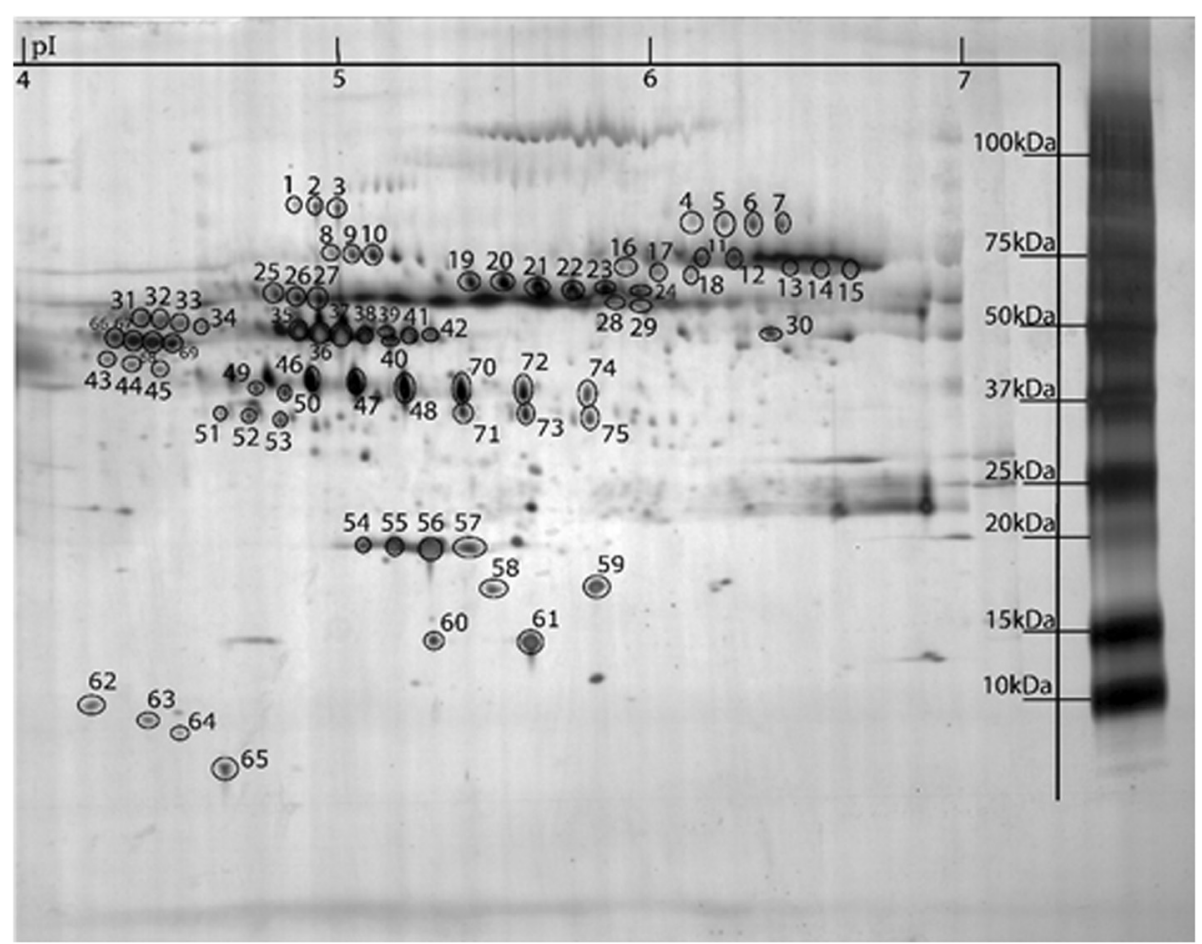

Fig. 2 A typical 2DE protein pattern of human plasma in pl range of 4-7. The marked spots refer to identified proteins in Table 1

While the levels of leucine-rich alpha-2- glycoprotein were higher in the farmer group, the levels of alpha-1Bglycoprotein were higher in the referent group (Table 3). Whether these proteins, too, are involved in inflammation or not remains unclear. The physiological role of leucine-rich alpha-2- glycoprotein is not known; however, its $33 \%$ sequence homology with a beta-type phospholipase A2 inhibitor [47] suggests the possibility that it might modulate inflammation and pain through inhibition of phospholipase A2 activity. As to alpha-1Bglycoprotein, decreased plasma levels of this protein were found in patients with rheumatoid arthritis [32] but little

Table 3 Proteins that were present differently in the plasma of farmers with MSD and their matched rural referents (RR)

\begin{tabular}{|c|c|c|c|c|c|c|}
\hline Spot & Protein & MSD vs RR & Accession number & OD (MSD) Mean $\pm(S D) \times 10^{3}$ & $\mathrm{OD}(\mathrm{RR})$ Mean $\pm(\mathrm{SD}) \times 10^{3}$ & $p$-value \\
\hline 311 & Alpha-2-HS-Glycoprotein & $\downarrow$ & P02765 & $4.768(3.556)$ & $7.720(2.386)$ & 0.046 \\
\hline 1318 & Leucine-rich alpha glycoprotein & $\uparrow$ & P02750 & $4.587(3.355)$ & $2.081(1.285)$ & 0.04 \\
\hline 1507 & Kininogen & $\uparrow$ & P01042 & $5.288(2.631)$ & $3.425(1.684)$ & 0.049 \\
\hline 2404 & Alpha1-anti trypsin & $\uparrow$ & P01009 & $12.938(7.270)$ & $7.799(6.398)$ & 0.04 \\
\hline 2607 & Kininogen & $\downarrow$ & P01042 & $6.885(3.786)$ & $10.114(2.964)$ & 0.03 \\
\hline 3802 & Alpha1-anti trypsin & $\downarrow$ & P01009 & $0.884(0.840)$ & $3.117(3.168)$ & 0.019 \\
\hline 4806 & Alpha-1B-glycoprotein & $\downarrow$ & P04217 & $4.677(2.359)$ & $6.487(1.138)$ & 0.01 \\
\hline 5507 & Vitamin D binding protein & $\downarrow$ & P02774 & $5.506(2.400)$ & $8.585(2.693)$ & 0.03 \\
\hline 6007 & Apolipoprotein A1 & $\downarrow$ & P02647 & $3.765(3.513)$ & $6.838(2.857)$ & 0.010 \\
\hline 6502 & Antithrombin III & $\downarrow$ & P01008 & $1.940(1.750)$ & $5.128(2.950)$ & 0.005 \\
\hline 6603 & Hemopexin & $\uparrow$ & P02790 & $7.613(5.647)$ & $2.377(2.225)$ & 0.019 \\
\hline 7101 & Haptoglobin & $\uparrow$ & P00738 & $5.455(1.552)$ & $3.573(1.382)$ & 0.008 \\
\hline 7602 & Hemopexin & $\uparrow$ & P02790 & $10.729(3.657)$ & $4.121(2.744)$ & 0.000 \\
\hline 8707 & Complement factor B & $\uparrow$ & P02790 & $2.468(2.920)$ & $1.226(2.029)$ & 0.022 \\
\hline 8811 & Serotransferrin & $\uparrow$ & P02787 & $8.633(3.460)$ & $5.355(2.047)$ & 0.010 \\
\hline
\end{tabular}

The spot numbers refer to the marked spots in Fig. 3

Arrow up $(\uparrow)$ indicates up-regulated and arrow down $(\downarrow)$ down-regulated proteins in farmers with MSD compared to RR 


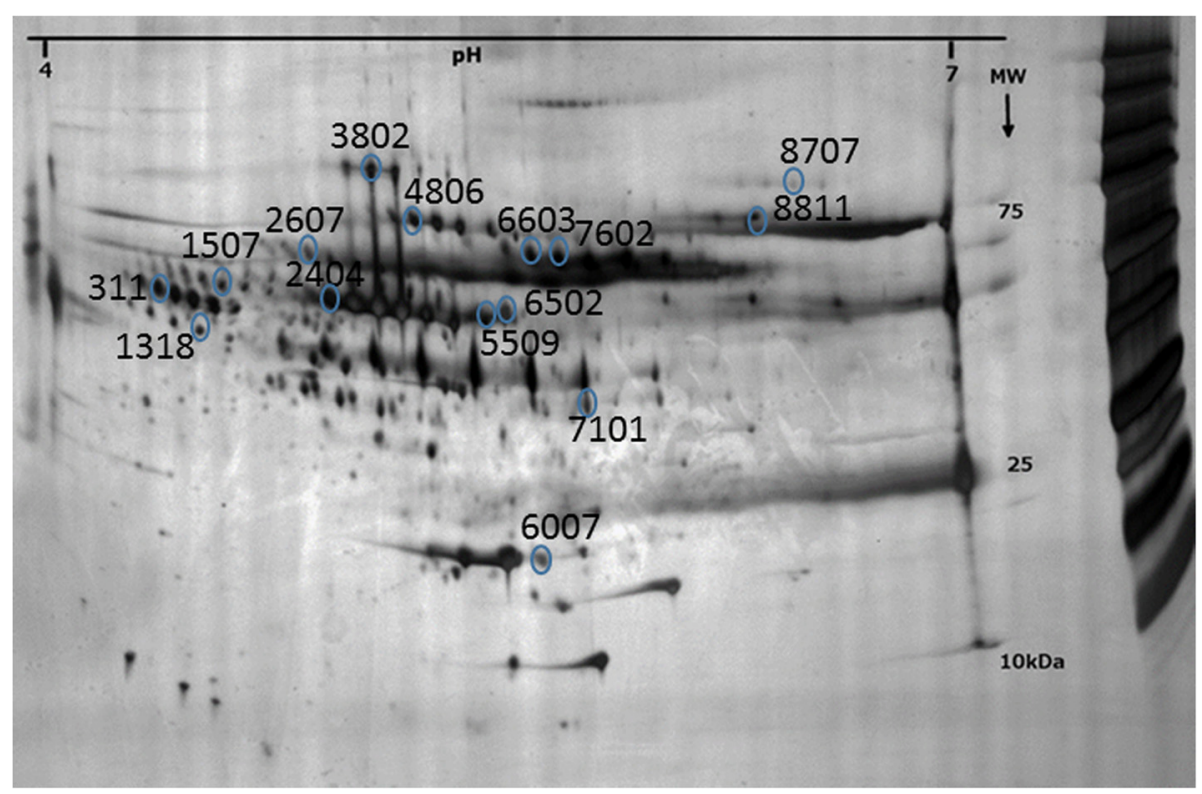

Fig. 3 Significantly changed proteins in farmers with musculoskeletal disorders compared to rural referents

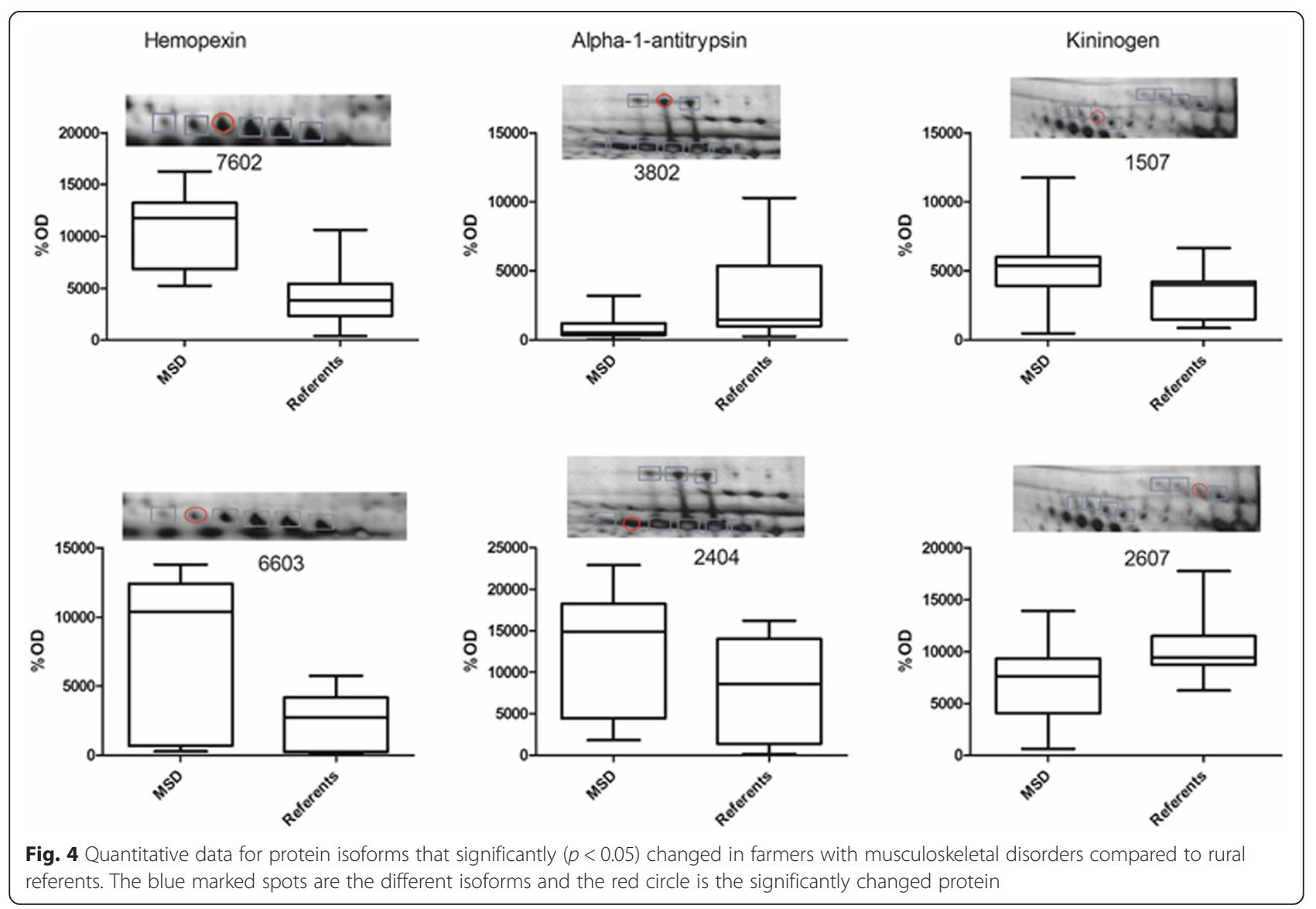


is known about the function of this protein and the biological relevance of this finding is therefore uncertain. The reason why serotransferrin (the major irontransporting plasma protein) was higher in the farmer group is also uncertain; interestingly, its plasma levels were affected in an experimental model of neuropathic pain [48]. Apolipoprotein A1 (ApoA1) has been shown to have anti-inflammatory properties and to reduce atherosclerosis [49]; one would expect, therefore, that farmers (who are at lower risk for cardiovascular disease than the general population) had higher (rather than lower) apoA1 than referents. On the other hand, the level of apoA1 in lipoproteins has been found to correlate positively with PCYOX1 [50], an enzyme which generates $\mathrm{H}_{2} \mathrm{O}_{2}$ and so probably plays a role in atherogenesis [51]. Based on this finding, Sun and coworkers suggested that high apoA1 content might be associated with increased risk of cardiovascular disease [50]. Further investigation is required to clarify the reason why farmers with MSD appear to have decreased serum levels of apo A1.

Although we were able to identify a protein profile that differentiates farmers with MSD from referents using proteomic techniques, the methods used in this study may pose some limitations. We used isoelectric points and molecular weight of the proteins to separate the proteins onto a two-dimensional gel. We were limited therefore to investigating proteins within a certain range of isoelectric points and molecular weight, thereby excluding several proteins that may be potential candidates for biomarkers of MSD in farmers. Furthermore, we used a depletion column to remove the high abundant proteins (albumin and IgG) before analysis these proteins give substantial background to the 2DE profiles and make analysis difficult [5]; it is not impossible that this procedure might have eliminated some other candidates. As to the protein resolution, we have little reason to believe that the methods used have posed further limitations; rather, an advantage of $2 \mathrm{DE}$ compared to other separation methods is the quality of protein resolution [52] as shown by the capability of resolving many post-translationally modified proteins that may appear as isoforms. Identity of each protein spot was determined by mass spectrometry, which is the method of choice for accurate probability based protein identification. Moreover, it is unlikely that the results are flawed by unacceptable analytical errors; densitometric analyses combined with silver staining of proteins are highly quantitative and a median coefficient of variation of approximately $8 \%$ has been reported using similar parameters as used in our procedure (i.e., fluorescent staining, PDQuest software) [53].

\section{Conclusions}

In conclusion, we have identified a number of proteins that are present differently in the plasma of farmers with MSD and their rural referents. Many of these proteins are known to be mediators or indicators of inflammation, supporting the hypothesis that farmers with MSD may be subject to a more systemic inflammation. The implication of these findings is worth considering. First, it is possible that the identified proteins may give clues to the biochemical changes occurring during the development and progression of MSD in farmers and so contribute to a deeper understanding of the pathogenetic mechanisms behind MSD and related symptoms/findings in other organ systems. Second, one or several or a combination of the identified proteins might possibly be used as a biomarker(s) of MSD in farmers. Much further investigation is therefore warranted, including comparisons of farmers with and without MSD and referents with and without MSD to elucidate how MSD protein picture relates to exposure. Third, if it turns out that a plasma biomarker(s) appears early during the development of MSD in farmers, this biomarker(s) might eventually be used to identify farmers who are at greater risk and to prevent progression of the disease process.

This study provides novel information about the biological mechanisms behind MSD in farmers and makes it possible to explain the link between health outcomes and the work environment. We identify biomarkers of systemic inflammation that contribute to better understanding of the pathophysiological processes involved in MSD. Although farmers are a relatively small occupational group in Sweden today, the identification of the causes of work-related MSD in this group may be a valuable tool for understanding of similar phenomenon in other groups. The results of this study thus may contribute to a better understanding of how problems in the musculoskeletal system generally arise.

\section{Ethics approval and consent to participate}

The cohort study has been approved by the Research Ethics Committee at the Karolinska Institute in Stockholm, Sweden, and by the Regional Ethics Board in Uppsala, Sweden. All men who participated in the health surveys gave their informed consent.

\section{Consent for publication}

Not applicable.

\section{Availability of data and materials}

The data set on which the conclusions of the paper rely are partly included in the manuscript. The study is not finished yet therefore additional data are available on request to corresponding author. 


\section{Additional file}

Additional file 1: The questionnaire for the musculoskeletal symptoms. (DOCX $16 \mathrm{~kb}$ )

\section{Abbreviations}

2DE: two-dimensional gel electrophoresis; MS: mass spectrometry; MSD: musculoskeletal disorders; VDBP: vitamin D-binding protein.

\section{Competing interests}

The authors declare that they have no competing interests.

\section{Authors' contributions}

Conceived and designed the experiments: AT, SH, CT and BG. Data collection of the questionnaires and clinical examinations: AT and SH. Performed the experiments: AC and BG. Analyzed the data: AC, CT and BG. All authors have contributed to write the manuscript, read and approved the final manuscript.

\section{Acknowledgement}

We would like to thank Louise Eskilsson, from Occupational and Environmental Medicine (Linköping, Sweden), for the valuable help with aliquoting of the plasma samples.

\section{Funding}

This study was supported by The Swedish Farmers' Foundation for Agricultural Research (H0935072) and The Swedish Rheumatism Association (R-420491)

\section{Author details}

'Division of Community Medicine, Department of Medical and Health Sciences, Faculty of Health Sciences, Linköping University and Pain and Rehabilitation Center, Anaesthetics, Operations and Specialty Surgery Center, Region Östergötland, Linköping SE-581 85, Sweden. ²Division of Neuro and Inflammation Science, Department of Clinical and Experimental Medicine, Linköping University, Occupational and Environmental Medicine Center Heart and Medicine Center, Region Östergötland, Linköping, Sweden. ${ }^{3}$ Department of Research and Development, Region Kronoberg, Växjö, Sweden. ${ }^{4}$ Department of Public Health and Caring Sciences, Family Medicine and Clinical Epidemiology Sections, Uppsala University, Uppsala, Sweden.

Received: 26 January 2016 Accepted: 3 May 2016

Published online: 10 May 2016

\section{References}

1. Thelin N, Holmberg S, Nettelbladt P, Thelin A. Mortality and morbidity among farmers, non-farming rural men and urban referents. a prospective population-based study. Int J Occup Environ Health. 2009;15:21-8.

2. Thelin A, Vingård E, Holmberg S. Osteoarthritis of the hip joint and farm work. Am J Ind Med. 2004:45:202-9.

3. Holmberg S, Thelin A, Stiernstrom E, Svardsudd K. The impact of physical work exposure on musculoskeletal symptoms among farmers and rural non-farmers. Ann Agric Environ Med. 2003;10:179-84.

4. Holmberg S, Thelin A, Stiernström EL, Svärdsudd K. Low back pain comorbidity among male farmers and rural referents: a population-based study. Ann Agric Environ Med. 2005:12:261-8.

5. Thadikkaran L, Siegenthaler MA, Crettaz D, Queloz PA, Schneider P, Tissot JD. Recent advances in blood-related proteomics. Proteomics. 2005:5:3019-34

6. Zhang Y, Jiang R, Guo T, Wu S, Ma W. MALDI-TOF-MS serum protein profiling for developing diagnostic models and identifying serum markers for discogenic low back pain. BMC Musculoskelet Disord. 2014;15:3-10

7. Stiernström EL, Holmberg S, Thelin A, Svärdsudd K. A prospective study of morbidity and mortality rates among farmers and rural and urban nonfarmers. J Clin Epidemiol. 2001:54:121-6.

8. Nerbrand C, Svärdsudd K, Hörte LG, Tibblin G. Geographical variation of mortality from cardiovascular diseases. The Project 'Myocardial Infarction in mid-Sweden'. Eur Heart J. 1991;12:4-9.
9. Holmberg S, Stiernström EL, Thelin A, Svärdsudd K. Musculoskeletal symptoms among farmers and Non-farmers: a population-based study. Int J Occup Environ Health. 2002;8:339-45.

10. Bradford MM. A rapid and sensitive method for the quantitation of microgram quantities of protein utilizing the principle of protein-dye binding. Anal Biochem. 1976;72:248-54.

11. Gorg A, Obermaier C, Boguth G, Harder A, Scheibe B, Wildgruber R, et al. The current state of two-dimensional electrophoresis with immobilized pH gradients. Electrophoresis. 2000;21:1037-53.

12. Ghafouri B, Stahlbom B, Tagesson C, Lindahl M. Newly identified proteins in human nasal lavage fluid from non-smokers and smokers using two-dimensional gel electrophoresis and peptide mass fingerprinting. Proteomics. 2002:2:112-20.

13. Olausson P, Gerdle B, Ghafouri N, Larsson B, Ghafouri B. Identification of proteins from interstitium of trapezius muscle in women with chronic myalgia using microdialysis in combination with proteomics. PLoS One. 2012;7:e52560

14. Banda NK, Thurman JM, Kraus D, Wood A, Carroll MC, Arend WP, et al. Alternative complement pathway activation is essential for inflammation and joint destruction in the passive transfer model of collagen-induced arthritis. J Immunol. 2006;177:1904-12.

15. Katz Y, Stav D, Barrt J, Passwelli JH. IL-13 results in differential regulation of the complement proteins C3 and factor B in tumor necrosis factor [TNF]-stimulated fibroblasts. Clin Exp Immunol. 1995;101:150-6.

16. Katz Y, Nadiv O, Rapoport MJ, Loos M. IL-17 regulates gene expression and protein synthesis of the complement system, C3 and factor B, in skin fibroblasts. Clin Exp Immunol. 2000;120:22-9.

17. Frenette J, Cai B, Tidball JG. Complement activation promotes muscle inflammation during modified muscle use. Am J Pathol. 2000;156:2103-10.

18. Wang Y, Kinzie E, Berger FG, Lim SK, Baumann H. Haptoglobin, an inflammation-inducible plasma protein. Redox Rep. 2001;6:379-85.

19. Huntoon KM, Wang Y, Eppolito CA, Barbour KW, Berger FG, Shrikant PA, et al. The acute phase protein haptoglobin regulates host immunity. I Leukoc Biol. 2008:84:170-81.

20. Maffei M, Funicello M, Vottari T, Gamucci O, Costa M, Lisi S, et al. The obesity and inflammatory marker haptoglobin attracts monocytes via interaction with chemokine [C-C motif] receptor 2 [CCR2]. BMC Biol. 2009:7:87.

21. Park HJ, Oh MK, Kim NH, Cho ML, Kim IS. Identification of a specific haptoglobin C-terminal fragment in arthritic synovial fluid and its effect on interleukin-6 expression. Immunology. 2013;140:133-41.

22. Tolosano E, Altruda F. Hemopexin: structure, function, and regulation. DNA Cell Biol. 2002:21:297-306.

23. Wiedermann CJ, Römisch J. The anti-inflammatory actions of antithrombin-a review. Acta Med Austriaca. 2002:29:89-92.

24. Gritti D, Malinverno A, Gasparetto C, Wiedermann CJ, Ricevuti R. Attenuation of leukocyte beta 2-integrin expression by antithrombin-III. Int J Immunopathol Pharmacol. 2004;17:27-32

25. Doi T, Adachi S, Takai S, Matsushima-Nishiwaki R, Kato H, Enomoto $Y$, et al. Antithrombin III suppresses ADP-induced platelet granule secretion: inhibition of HSP27 phosphorylation. Arch Biochem Biophys. 2009:489:62-7.

26. Huang CY, Sheen-Chen SM, Ho HT, Tang RP, Eng HL. Antithrombin-III attenuates hepatocyte apoptosis in bile duct ligated rat: a striking cellular change. Surg Innov. 2010;17:132-5

27. Isik S, Tuncyurek P, Zengin NI, Demirbag AE, Atalay F, Yilmaz S, et al. Antithrombin prevents apoptosis by regulating inflammation in the liver in a model of cold ischemia/warm reperfusion injury. Hepatogastroenterol. 2012;59:453-7.

28. Sun HM, Hong LZ, Shen XK, Lin XQ, Song Y, Shi Y. Antithrombin-III without concomitant heparin improves endotoxin-induced acute lung injury rats by inhibiting the activation of mitogen-activated protein kinase. Chin Med J. 2009:122:2466-71

29. Li W, Zhu S, Li J, Huang Y, Zhou R, Fan X, et al. A hepatic protein, fetuin-A, occupies a protective role in lethal systemic inflammation. PLoS One. 2011; 8:e16945.

30. Minas M, Mystridou P, Georgoulias P, Pournaras S, Kostikas K, Gourgoulianis $\mathrm{KI}$. Fetuin-A is associated with disease severity and exacerbation frequency in patients with COPD. COPD. 2013:10:28-34.

31. Oncu K, Yazgan Y, Tanoglu A, Kaplan M, Ermis F, Ipcioglu OM, et al. Can serum fetuin-A be regarded as an inflammatory marker among patients with familial Mediterranean fever? Dig Dis Sci. 2013;58:3212-7. 
32. Doherty NS, Littman BH, Reilly K, Swindell AC, Buss JM, Anderson NL. Analysis of changes in acute-phase plasma proteins in an acute inflammatory response and in rheumatoid arthritis using two-dimensional gel electrophoresis. Electrophoresis. 1998;19:355-63.

33. Sato H, Kazama JJ, Wada Y, Kuroda T, Narita I, Gejyo F, et al. Decreased levels of circulating alpha2-Heremans-Schmid glycoprotein/Fetuin-A [AHSG] in patients with rheumatoid arthritis. Intern Med. 2007;46:1685-91.

34. Kim JC, Kim JY, Yeom SR, Jeong BY, Hwang HZ, Park KJ, et al. 2-D DIGE and MS/MS analysis of protein serum expression in rats housed in concrete and clay cages in winter. Proteomics. 2008:8:3632-44.

35. Hattori N, Oda S, Sadahiro T, Nakamura M, Abe R, Shinozaki K, et al. YKL-40 identified by proteomic analysis as a biomarker of sepsis. Shock. 2009;32 393-400.

36. Jeng L, Yamshchikov AV, Judd SE, Blumberg HM, Martin GS, Ziegler TR, et al. Alterations in vitamin D status and anti-microbial peptide levels in patients in the intensive care unit with sepsis. J Transl Med. 2009;23:28.

37. Oh YM, Ma TZ, Kwak YG, Eun JP. Proteomic evaluation to identify biomarkers for carpal tunnel syndrome: a comparative serum analysis. Connect Tissue Res. 2013;54:76-81.

38. Yamamoto N, Naraparaju VR. Structurally well-defined macrophage activating factor derived from vitamin D3-binding protein has a potent adjuvant activity for immunization. Immunol Cell Biol. 1998;76:237-44.

39. Nagasawa H, Uto Y, Sasaki H, Okamura N, Murakami A, Kubo S, et al. Gc protein [vitamin D-binding protein]: Gc genotyping and GcMAF precursor activity. Anticancer Res. 2005;25:3689-95.

40. Gumireddy K, Reddy CD, Swamy N. Mitogen-activated protein kinase pathway mediates DBP-maf-induced apoptosis in RAW 264.7 macrophages. J Cell Biochem. 2003;90:87-96.

41. Ueno A, Oh-ishi S. Roles for the kallikrein-kinin system in inflammatory exudation and pain: lessons from studies on kininogen-deficient rats. J Pharmacol Sci. 2003;93:1-20.

42. Del Rosso M, Fibbi G, Pucci M, Margheri F, Serrati S. The plasminogen activation system in inflammation. Front Biosci. 2008;1:4667-86.

43. Kashuba E, Bailey J, Allsup D, Cawkwell L. The kinin-kallikrein system: physiological roles, pathophysiology and its relationship to cancer biomarkers. Biomarkers. 2013;18:279-96.

44. Cassim B, Shaw OM, Mazur M, Misso NL, Naran A, Langlands DR, et al. Kallikreins, kininogens and kinin receptors on circulating and synovial fluid neutrophils: role in kinin generation in rheumatoid arthritis. Rheumtol [Oxford]. 2009;48:490-6.

45. Cox DW, Huber O. Rheumatoid arthritis and alpha-1-antitrypsin. Lancet. 1976;5:1216-7

46. Duckers JM, Shale DJ, Stockley RA, Gale NS, Evans BA, Cockcroft JR, et al. Cardiovascular and musculskeletal co-morbidities in patients with alpha 1 antitrypsin deficiency. Respir Res. 2010;7:173.

47. Tan EC, Bahrami S, Kozlov AV, Kurvers HA, Ter Laak HJ, Nohl H, et al. The oxidative response in the chronic constriction injury model of neuropathic pain. J Surg Res. 2009;152:84-8.

48. Okumura K, Ohkura N, Inoue S, Ikeda K, Hayashi K. A novel phospholipase A2 inhibitor with leucine-rich repeats from the blood plasma of Agkistrodon blomhoffii siniticus. Sequence homologies with human leucine-rich alpha2-glycoprotein. J Biol Chem. 1998;31:19469-75.

49. Tuteja S, Rader DJ. High-density lipoproteins in the prevention of cardiovascular disease: changing the paradigm. Clin Pharmacol Ther. 2014. 96:48-56.

50. Sun HY, Chen SF, Lai MD, Chang TT, Chen TL, Li PY, et al. Comparative proteomic profiling of plasma very-low-density and low-density lipoproteins. Clin Chim Acta. 2010;411:336-44.

51. Banfi C, Brioschi M, Barcella S, Wait R, Begum S, Galli S, et al. Proteomic analysis of human low-density lipoprotein reveals the presence of prenylcysteine lyase, a hydrogen peroxide-generating enzyme. Proteomics. 2009;9:1344-52.

52. Smilansky Z. Automatic registration for images of two-dimensional protein gels. Electrophoresis. 2001;22:1616-26.

53. Raman B, Cheung A, Marten MR. Quantitative comparison and evaluation of two commercially available, two-dimensional electrophoresis image analysis software packages, Z3 and Melanie. Electrophoresis. 2002;23:2194-202.

\section{Submit your next manuscript to BioMed Central and we will help you at every step:}

- We accept pre-submission inquiries

- Our selector tool helps you to find the most relevant journal

- We provide round the clock customer support

- Convenient online submission

- Thorough peer review

- Inclusion in PubMed and all major indexing services

- Maximum visibility for your research

Submit your manuscript at www.biomedcentral.com/submit
Biomed Central 